\title{
Chapter 14 \\ Educating for Environmental Citizenship in Non-formal Frameworks for Secondary Level Youth
}

\author{
Demetra Paraskeva-Hadjichambi, Daphne Goldman, \\ Andreas Ch. Hadjichambis, Gema Parra, Katharina Lapin, \\ Marie-Christine Knippels, and Frans Van Dam
}

\subsection{Characteristics of Non-formal Education Promoting the Attributes of an Environmental Citizen}

For the purpose of this chapter, it is valuable to briefly distinguish between nonformal and informal education - terms that are often used interchangeably. Nonformal and informal learning takes place in out-of-school environments and settings (e.g. libraries, exhibits, museums, science centres, zoos, aquaria, botanical gardens and wildlife-based environments, community centres and organisations, etc.).

\footnotetext{
D. Paraskeva-Hadjichambi $(\bowtie) \cdot$ A. Ch. Hadjichambis

Cyprus Ministry of Education and Culture, Nicosia, Cyprus

Cyprus Centre for Environmental Research and Education, CYCERE, Lemesos, Cyprus e-mail: demhad@ucy.ac.cy; a.chadjihambi@cytanet.com.cy

D. Goldman

Department of Environmental Science and Agriculture, Faculty of Education, Beit Berl

College, Kfar Saba, Israel

e-mail: dafnag@netvision.net.il

G. Parra

Departamento de Biología Animal, Biología Vegetal y Ecología, University of Jaén,

Jaén, Spain

e-mail: gparra@ujaen.es

K. Lapin

Austrian Research Centre for Forests (BFW- Bundesforschungs- und Ausbildungszentrum für Wald, Naturgefahren und Landschaft), Vienna, Austria

e-mail: katharina.lapin@bfw.gv.at

M.-C. Knippels · F. Van Dam

Freudenthal Institute, Utrecht University, Utrecht, The Netherlands

e-mail: M.C.P.J.Knippels@uu.nl; F.W.vanDam@uu.nl
} 
Scholars (Eshach 2007; Falk 2006) assert that the distinction should take into account not only the physical environment in which learning takes place but other aspects, especially the underlying motivation and interest of the learner to learn, the social contexts and socially-constructed nature of learning as well as the organisation of the learning and assessment. According to Eshach, informal learning refers to learning that may happen in spontaneous situations that happen in people's lives and other unstructured activities. Thus, the learning is open, intrinsically motivated (i.e. individual's choice) and is usually individually lead (control over learning). Informal learning is often referred to as 'free-choice' learning (NAAEE 2009; Ballantyne and Packer 2005).

Conversely, non-formal learning occurs in a planned but highly adaptable manner in institutions, organisations and situations beyond the spheres of formal or informal education (Eshach 2007; Silberman-Keller 2003). While it is mediated, the motivation for learning may arise from the learner. An additional distinction relevant to the nature of learning is based on the frequency at which the places where learning occurs are visited. Accordingly, informal learning will happen in places where people's daily lives take place, e.g. homes, neighbourhoods and local playgrounds or school grounds during breaks. Spontaneous informal learning may, in principle, be experienced in places associated with free choice learning, such as zoos, museums and other such settings. As such visits can be infrequent, they are often organised and may include structured activities (especially when visited as part of a school programme), thus the type of learning that often occurs is non-formal (Esach 2007). Table 14.1 compares formal, informal and non-formal learning.

While the formal educational system is traditionally viewed as a main framework for conducting Education for Environmental Citizenship, both non-formal and informal are recognised as important arenas for educating the public about the environment (Hollweg et al. 2011; NAAEE 2009; Ballantyne and Packer 2005; UNESCO 1978) and as arenas for lifelong learning, which is acknowledged as a crucial component towards building sustainable societies and futures. Since the average citizen spends only about $3 \%$ of their lifetime in school, the ability to

Table 14.1 Differences among formal, informal and non-formal learning (taken from Eshach 2007)

\begin{tabular}{l|l|l}
\hline Formal & Non-formal & Informal \\
\hline Usually at school & At institution out of school & Everywhere \\
\hline May be repressive & Usually supportive & Supportive \\
\hline Structured & Structured & Unstructured \\
\hline Usually prearranged & Usually prearranged & Spontaneous \\
\hline $\begin{array}{l}\text { Motivation is typically more } \\
\text { extrinsic }\end{array}$ & $\begin{array}{l}\text { Motivation may be extrinsic but } \\
\text { typically more intrinsic }\end{array}$ & $\begin{array}{l}\text { Motivation is mainly } \\
\text { intrinsic }\end{array}$ \\
\hline Compulsory & Usually voluntary & Voluntary \\
\hline Teacher-led & May be guide- or teacher-led & Usually learner-led \\
\hline Learning is evaluated & Learning is usually not evaluated & $\begin{array}{l}\text { Learning is not } \\
\text { evaluated }\end{array}$ \\
\hline Sequential & Typically non-sequential & Non-sequential \\
\hline
\end{tabular}


access, critically evaluate and utilise information must continue throughout people's lives. Non-formal and informal settings offer the opportunity for such lifelong learning. Additionally, these frameworks can support students' learning in formal education and this is increasingly acknowledged and utilised (for example, Bell et al. 2009). Since most learning is attained outside of schools, which is especially true for environmental learning, there is increasing recognition of the significant role of various free-choice learning venues (Table 14.2) in peoples' lifelong environmental learning (Falk, 2006).

In recent years, the learning ecosystem has become prominent in which formal, non-formal and informal learning experiences are studied in an integrative way. According to Bevan (2016, p. 18), "Ecological theories of learning are based on the idea that learning develops over time and in multiple settings. Learning opportunities are made possible and shaped by the learning ecology that one inhabits. A learning ecology is the physical, social, and cultural context in which learning takes place". Educators who design interventions for learning ecologies will develop a learning module for formal education, which then extends to the home situation (informal) or is combined with a visit to a science centre (non-formal). Environmental education in general, and Environmental Citizenship in particular, could benefit from an integrative learning ecology approach. The question in learning ecosystems is how to create rich ecologies of learning that support momentum for individuals throughout their lives and provide resources so that they can navigate specific pathways. These momentums are often curiosity-driven and individuals may choose to look for resources inside and outside formal education.

Table 14.2 Free-choice venues for learning about the environment. (Adapted from Falk 2006)

\begin{tabular}{l|l}
\hline Generic group & Exemplar Venues \\
\hline Museums & $\begin{array}{l}\text { Natural history museums, science centres/museums, zoos, } \\
\text { aquariums, botanical gardens, arboretums, nature centres }\end{array}$ \\
\hline $\begin{array}{l}\text { Environmental education } \\
\text { centres }\end{array}$ & Structured programmes sometimes linked to formal curriculum \\
\hline Parks & Local, regional, national \\
\hline Ecotourism sites & $\begin{array}{l}\text { Whale-watching and marine watching tours, safaris and wildlife } \\
\text { encounter trips, lodges in natural areas, Earthwatch expeditions } \\
\text { (citizen science) }\end{array}$ \\
\hline Audio-visual media & TV programmes, films and videos, radio \\
\hline Printed media & Newspapers, magazines and periodicals \\
\hline Electronic media & $\begin{array}{l}\text { Internet, social networks (Facebook and Twitter), petition web sites } \\
\text { (Change.org) }\end{array}$ \\
\hline $\begin{array}{l}\text { National Community- } \\
\text { based organisations }\end{array}$ & $\begin{array}{l}\text { World Wildlife Fund, Sierra Club (USA), Society for Protection of } \\
\text { Nature (SPNI). }\end{array}$ \\
\hline Clubs and movements & $\begin{array}{l}\text { YMCA and YWCA, boys and girls clubs, scouts, youth movements, } \\
\text { Elderhostel (USA organisation of educational travel tours for older } \\
\text { adults). }\end{array}$ \\
\hline $\begin{array}{l}\text { International days } \\
\text { celebration }\end{array}$ & \begin{tabular}{l} 
Sea clean-up day \\
\hline Home environment
\end{tabular} \\
\hline
\end{tabular}


While non-formal education shares the attribute of being mediated with formal education, a major assumption of non-formal education is that social and educational goals can, and should, be realised via content and principles that deviate from rigid formal education structure. The following presents several characteristics of non-formal education and their relevance to developing Environmental Citizenship.

- Conversation - Conversation in peer communities under guidance (youth worker or guide) is a generative element of non-formal education that facilitates learning (Goldman et al. 2017; Kiilakoski and Kivijärvi 2015). In the context of environmental education, Orr (1992) acknowledges 'good conversation' as one of the components of education that can develop ecological literacy. It acknowledges diversity (existence and interest of others), is not neutral - through it people define themselves in relation to another (people and their environment), and it has structure and purpose (Orr 1992). Through these, conversation expands people's experiences, promotes learning and supports democracy via the practice of criticising political life. Less opportunity for such 'good' conversation exists under the common circumstances of governed formal education curricula.

- Networks - These define the structure of non-formal education organisations and reflect their communicative pattern in contrast to the hierarchical unified structure of the formal education system, and facilitate a multidirectional and more symmetric form of communication (Silberman-Keller 2003). In Capra's (1996) concept of eco-literacy (learning from ecological communities), a network implies interdependence, thus the success of the community as a whole depends on the success of its individuals and vice versa. Comprehending interdependence means understanding relationships - a shift in perception from focus on objects to focus on relationships and patterns in these relationships. This type of perception is characteristic of systems thinking, which is uncontested as a key toward sustainability and educating for sustainability (Senge 2012; Capra 1996). Thus, from both the communication perspective and developing ecological literacy, the goal of promoting sustainability networking contains a crucial component for achieving social change.

- Tight versus loose learning spaces - Kiilakoski and Kivijärvi (2015), in the context of Finish Youth Clubs as spaces for non-formal learning, distinguish between tight and loose learning spaces. Tight spaces presume functionality (e.g. a preplanned rigid schedule) and homogeneity. Schools are the classical example of tight spaces. Conversely, non-formal learning environments are loose learning spaces - they enable heterogeneity, change, adaptable learning opportunities, and an emphasis on negotiation as opposed to rigid curricula or rules.

- Educational institution - While school is the only arena of formal education, the venues for non-formal education are diverse, and include clubhouses, communes, community centres, youth-group branches, etc. Silberman-Keller (2003) asserts that the participants in non-formal educational activities view their nonformal learning environment as an accommodating and secure "alternative home" and as such do not experience alienation, lack of identity and lack of instrumental functionality that characterize the structured school or workplace, where young people and adults spend their compulsory time. 
- Mutual development - From the perspective of socialisation, non-formal pedagogy aspires for mutual development - the group will develop as long as its participants develop and the individual will develop as long as the group develops. This provides a positive metaphor for the reciprocal relationship between the individual and society and can thus enhance the social responsibility required of environmentally responsible citizens (Goldman et al. 2017).

- Experiential learning - Learning that involves social involvement contributes to developing a sense of responsibility, evoking feelings and changing attitudes, environmental awareness, and a sense-of-place (e.g. physical, cultural and community identity), that together promote environmentally sustainable behaviour.

This brief consideration of various characteristics of informal and non-formal education and their relevance to environmental learning/educating for sustainability underlines the potential contribution of these frameworks in developing many of the cognitive and, importantly, affective components of Environmental Citizenship. From the affective dimension, these settings inspire curiosity and exploration, evoke feelings and may change attitudes, nurture a sense of personal and community identity, and can influence people's decision-making concerning ethical and moral issues relating to daily lives (Ballantyne and Packer 2005). Falk (2006) claims that “...such experiences invariably result in a more knowledgeable individual possessing an incrementally enhanced motivation and capacity to learn more in the future..." (p. 266). The non-rigid but guided process that takes place in non-formal educational situations can facilitate the development of rational and authentic decision-making. Additionally, non-formal settings offer a more open (loose) framework that enables people to interpret experiences according to a personal perspective and personal interests, as well as to construct a personal worldview. Falk (2006) identifies an additional benefit of free-choice learning that is associated with out-of-school and, specifically, non-formal learning settings. This type of learning is bottom-up and individually-driven (as opposed to top-down institutionallydriven), and it provides the opportunity for lifelong learning, which, in a world that is becoming progressively knowledge-driven, is acknowledged as crucial. The importance of non-formal and informal education frameworks as arenas for engaging citizens in sustainability (Goldman et al. 2017) stems from these attributes.

\subsection{Pedagogies, Teaching Tools and Learning Schemes of Secondary Non-formal Education for Promoting Environmental Citizenship}

Activities in non-formal settings can provide innovative alternatives to class-based teaching systems. They can stimulate personal interaction in problem solving, develop the willingness and the competences for critical and active engagement in individual and collective spheres within democratic contexts, and take into account inter-generational equality and justice. Therefore non-formal settings for secondary education level could contribute to Education for Environmental Citizenship by pro- 
viding the opportunity and conditions that enable young people to acquire the body of knowledge as well as the necessary skills, values, attitudes and pro-environmental actions that an Environmental Citizen should be equipped with. In doing so, young people will be empowered and motivated to act and participate in society as an agent-of-change in the direction of solving contemporary environmental problems, preventing the creation of new environmental problems, achieving sustainability, and restoring our (human) relationships with nature.

Non-formal activities of EE have focused primarily on individual changes, especially on attitude and behavioural changes related to environmental aspects (Kool 2012). By building knowledge and environmental behaviours, teachers who have committed themselves to environmental learning have looked to environmental literacy and positive nature-based experiences for the development of ecologically responsible citizens (Hungerford 2010; Marcinkowski 2010). However, more recently, environmental educators and researchers support the need to move beyond a central focus on individual changes in attitude and behaviour, to collectively build a better understanding of environmental learning processes aimed at socioecological change (Orr 2004). Thus, EE practices that only attempt to change individual behaviour or increase students' knowledge of environmental issues will fall short of promoting Environmental Citizenship. EE is not detached from environmental policy (De Carvalho and Lemos de Souza 2018). Thus, the role of EE is to provide students with the opportunity to learn how to be active Environmental Citizens within their communities through civic participation and active engagement, while helping students to understand the structural and systemic roots of social and environmental problems.

How can we collectively develop in today's youth the knowledge, skills and competencies required to be ecologically and socially responsible Environmental Citizens? What kinds of pedagogies and learning experiences could potentially develop students' skills for deep civic participation, contributing to environmental and social change?

The following pedagogies, teaching tools and learning schemes of non-formal education could be complementary to formal secondary education in promoting Education for Environmental Citizenship.

\subsubsection{Place-Based Education}

The Place-based framework and its variations (e.g. expeditionary learning, pedagogy of place, problem-based learning, service-learning) seeks to make "the boundaries between schools and their environments more permeable by directing at least part of a students' school experiences to local phenomenon ranging from culture and politics to environmental concerns and the economy" (Smith 2007, p. 190). Such an approach does not diminish the importance of conceptual understanding and skills as a result of the educational process; on the contrary, these elements are integrated into an experiential and multidisciplinary learning environment in non- 
formal sites that also have the potential to contribute positively to the community (Paraskeva-Hadjichambi et al. 2012; Gruenewald 2003.) Some scholars prompt teachers to introduce critical pedagogy into a place-based educational approach. They argue that students should not only be involved in and interact with the local context, but also be encouraged to critically examine local issues of power, ethnicity and alternative ways of teaching (Tuck et al. 2014; Cole 2007, Gruenewald 2003). Gruenewald (2003) argues that through place-based learning, students should be guided through a 'reinhabitation' process where they criticise the historical and contemporary contexts of their places, while also working to restore social and environmental practices (Smith 2007, p. 192).

EE practices that aim to connect students to their local environment and community and provide the opportunity to participate in the social dimension of a place, have the potential to promote the form of Environmental Citizenship supported in this chapter. The power of place-based learning lies in its ability to offer students genuine opportunities to participate in making positive changes in their local communities, leaving students with a higher "sense of their own agency and collective capacity" (Smith 2007, p. 192). "Place-based educational experiences in non-formal settings are connecting secondary school students with their communities and regions in ways that would probably not otherwise occur. Such learning lays the groundwork for civic participation" (Smith 2007, p. 203).

Place-based education can also help connect with the places where people live and the natural environment, creating a healthy relationship with nature (ENEC 2018). Scholars begin to recognise the important role played by the 'sense of place' in contributing to environmental concern and the motivation of people to act in environmental ways (e.g., Scannell and Gifford 2010; Stedman 2002; Vorkinn and Riese 2001). While place-based pedagogy does not explicitly define the concept of place, researchers have given recent attention to this relationship (Kudryavtsev et al. 2012; Semken and Freeman 2008, Vaske and Kobrin 2001). Of course, this is an area that is worth more empirical work, but it highlights the effectiveness of placebased education by linking people with their local community so that they consider themselves as citizens of their community. It encourages people to "to think and act as members of the public - not as consumers or producers or private persons, but as citizens who have a stake in maintaining a vital public realm" Dagger (2003, p. 41). This is very important for the empowerment of Environmental Citizens as described by ENEC (2018).

\subsubsection{Civic Ecology Education}

Civic ecology pedagogy (Tidball and Krasny 2010) can provide another example of how Environmental Citizenship could be promoted in non-formal settings. Civic ecology is defined as "stewardship practices that integrate social and environmental values within a social - ecological systems framework ... where participants act as stewards of their environment through practices such as community gardening, 
community forestry, and watershed restoration" (Tidball and Krasny 2010, p. 466). These practices create place-based learning in real-life resource management environments, allowing for an experiential and participatory learning process, while enhancing ecosystem and social health, which they call the 'ecology of environmental education' (Tidball and Krasny 2010). Civic ecology includes “urban environmental education programs that engage youth in community-based stewardship to restore" urban habitats, which incorporate both 'nature contact' and "democratic deliberation" (Tidball and Krasny 2010, p. 5). In this way, civic ecology education is inherently politically oriented, linking participants with developing movements such as civic environmentalism (Light 2003; Shutkin 2001) and the renewal of citizens (Sirianni and Friedland 2001).

Civic ecology education is an approach that combines traditional EE with civic engagement or service learning. Such a model provides a more exciting framework for promoting Environmental Citizenship, which goes beyond individual knowledge, attitudes and behaviours, in order to empower individuals to engage in the democratic processes required to meet the urgent need for sustainability. In addition, in civic ecology education, citizenship is treated as a collective enterprise, both in terms of strengthening the civic commons (Light 2003), and by challenging the existing institutional structures for the resumption of a democracy that favours sustainability (Maniates 2001). In this way, Education for Environmental Citizenship is more than just the promotion of individual virtues or changes in behaviour towards better environmental goals. It is a collective action based on practices where local communities can 'do something together' (Light 2002, p. 167).

\subsubsection{Ecojustice Pedagogy}

Ecojustice pedagogy could promote Environmental Citizenship of secondary school students in non-formal settings, since it calls for time spent in "out-of- classroom spaces and places; experiencing the knowledges of different cultures and cultural relationships to place; gaining a diversity of natural history knowledge; and developing community relationships and actions" (McKenzie 2008, p. 366).

Ecojustice pedagogy, which bridges western scientific knowledge with traditional ecological knowledge, combined with a multidisciplinary approach to learning, helps us move beyond the binary and disconnect. As a result, science and environmental learning - which is often abstract and extremely complex when taught in a classroom and from a textbook - becomes much more accessible, visible and relevant to students. Students can take this 'personal knowledge' and transfer and apply it to their daily lives in their homes, despite of geographic, socio-cultural and socio-economic diversity.

Ecojustice pedagogy incorporates a relationship-oriented, ecological conceptual framework that supports a wider global worldview. It adds an ecological lens to social justice. In other words, it extends the values of justice to include the environment and 'environmental racism' (Paraskeva-Hadjihcambi et al. 2015; Bowers 
2002). Ecopedagogy, which is within the broader theory of ecology, offers a valuable pedagogical lens that help to establish epistemological elements of ecological thinking in meaningful practice.

Through ecojustice education, students become familiar with ecologically sustainable practices of different cultures and prioritise pupils' participation in 'noncommodified aspects of community life' (Bowers 2002, p. 21). Additional strategies for implementing ecojustice pedagogy include: learning principles of ecological design; regenerating non-commoditized skills, knowledge, and relationships of self-reliance; and democratizing technology and science (Bowers 2002, pp. 30-32).

\subsubsection{Action Competence}

EE in authentic inquiry and action along with civic engagement is more appropriate in non-formal conditions for facilitating the kind of Environmental Citizenship required for sustainability (Berkowitz et al. 2005). In order to achieve a deep transformation of the community, an emerging trend is the development of 'environmental action' or 'action competence' in young people as a critical objective of environmental learning (Schusler and Krasny 2010; Jensen and Schnack 1997). Given that research on the EE explores the learning process for youth empowerment to participate in environmental action in the public sector (Almers 2013; Arnold et al. 2009), discussions are also taking place on the growing relationship between environment, science and civics education. These interesting discussions direct the emerging trend of environmental and scientific learning with the aim of active democratic citizenship (Wals and Jickling 2009; Gough and Scott 2007).

As an educational approach, environmental action does not aim to modify specific behaviours such as energy saving or recycling, but rather to bind youth to develop action strategies for environmental issues they consider relevant. It involves joint decision-making, which happens when adults and young people work together to design, implement and evaluate a project, whether the project is started by young people or adults (Schusler and Krasny 2010; Jensen and Schnack 1997).

Several examples of young people taking environmental action have been documented in educational practice:

- Natural environmental renovations (e.g.: tree planting to stabilise streambanks, transformation of empty lots into community gardens).

- Community education (e.g.: organising community information fairs, producing educational tools such as newsletters or videos).

- Inquiry (e.g.: community evaluations, surveys and mapping, scientific experiments designed to update or evaluate the action).

- Public problem analysis and support for policy change (e.g.: research and analysis of the environmental impacts of on-site waste water treatment regulations and presentation of policy recommendations to a state legislative committee).

- Products or services that contribute to community progress (e.g.: sustainable food for sale in a neighbouring rural market). 


\subsubsection{Socio-Scientific Inquiry-Based Learning}

The Socio-Scientific Inquiry-Based Learning (SSIBL) approach is another pedagogy that can foster democratic citizenship in general and Environmental Citizenship in specific, in-formal and non-formal settings (Amos et al. in press; Knippels and van Harskamp 2018; Levinson 2018; Levinson et al. 2017). The core of the approach is 'inquiry' into personal, social, global and scientific aspects of a controversial issue, such as environmental issues. The SSIBL approach draws together three interacting pillars - Inquiry Based Science Education, Socio-Scientific Issues and Citizenship Education - within the umbrella of Responsible Research and Innovation. The latter aims at bringing together various stakeholders (e.g.: consumers, interest groups, scientists, policy-makers, businesses) to produce realistic, balanced, just, and ethically-based outcomes to the innovation process covering the entire Research and Design process from its inception to distribution of social goods. SSIBL operationalised this aim broadly within school education, and more specifically within science education.

The SSIBL approach is based on learning through asking authentic questions about controversial issues arising from the impacts of science and technology in society. These questions are open-ended, they involve participation by concerned parties, and are aimed at solutions that help to enact change. The SSIBL approach consists of three key elements:

- Raising authentic questions about controversial issues arising from the impact of science and technology in society [Ask].

- Integrating social and scientific inquiry to explore these open-ended questions [Find out].

- Formulating solutions which help to enact change [Act].

This approach aims to: (1) encourage young people to participate in research and innovation issues that are influenced by science and technology; (2) promote interest in STEM; and (3) support young people in acting as knowledgeable social agents through inquiry.

\subsection{Examples of Secondary Non-formal Settings and Programmes Suitable for Promoting Education for Environmental Citizenship}

The following examples illustrate some non-formal settings and programmes that could promote Education for Environmental Citizenship. These case studies implement the pedagogies previously described (see sect. 14.2). It is important to clarify that most of them are based on the philosophy of Education for Sustainability, however, many have characteristics of Education for Environmental Citizenship. 


\subsubsection{Environmental Education Centres as Non-formal Settings Promoting Education for Environmental Citizenship: "Environmental Crime on the Coast", Cyprus}

The term 'environmental centre' is internationally used and covers centres outside of school frames with a variety of goals, activities and organisational structures. They are therefore termed as Outdoor Education Centres, (e.g. England), Field Studies Centres, (Mexico), Campus (USA, Hong Kong.), and National Park Centres, (Kruger National Park, South Africa).

Environmental education centres provide a basic link between non-formal and formal EE through structured programmes for students. The short time spent on visits often does not allow a full response to the goals of Education for Environmental Citizenship, but at least provides the opportunity for students to experience other forms of learning exclusively dedicated to the environment away from school, where the possibility to combine theory with a closer contact with the environment is offered.

The Cyprus Centre for Environmental Research and Education (CYCERE) is one of the most active environmental organisations in Cyprus, implementing innovative non-formal environmental education programmes related to the field of Education for Environmental Citizenship. "Environmental Crime on the Coast" is an example of such an educational programme. This programme is directed to secondary school students, age 13-18, and promotes the conceptual understanding of environmental issues, the cultivation of scientific and problem solving skills, as well as the development of environmental attitudes, values and awareness of students on the coastal ecosystem through a holistic and experiential learning approach. The methodological approaches adopted follow the principles and the philosophy of Environmental Education (EE) and Education for Sustainability (EfS), fostering team spirit and cooperation (Hadjichambis et al. 2015).

This daylong programme motivates students to participate in a sequence of activities, which emphasise both theoretical and practical aspects. It is organised in a way that supports the understanding of environmental concepts and issues and engages students into an exciting learning adventure.

\section{Students'Mission}

Students arrive at the coast and are informed that as members of the "Environmental Crime Investigation Department" they are invited to investigate a crime related to the coastal area. Solving the mystery requires students to go through different data collection stations and evaluate evidence by participating in various experiential activities.

2. Inquiry

(a) The ecosystem: Students gather information from scientific articles, data regarding abiotic and biotic factors and they become familiar with the eco- 
system of sand dunes. They also study the process of sand dune creation and development through experimental and playful ways.

(b) Food web: Using the evidence they collect about the food relations of the coastal living organisms, students discover the food web of the coastal ecosystem. They deepen their understanding on concepts of food relations while identifying plants and animals of the coast and their interactions.

(c) The effect of garbage: Students discover evidence relating to the decomposition rate of several materials and their impact on the coastal ecosystem. Through the data collected students awaken environmentally and realise the impact that anthropogenic waste can have on the coast and the natural ecosystems in general.

(d) Coast and Humans: Students identify several issues that are directly related to human presence on the Coast and the consequences of anthropogenic activities on the ecosystem. They explore and outline the relationships between humans and the coast and become aware of the importance of sustainable coastal management and protection developing positive environmental attitudes and values.

\section{Actions in Community}

Students returning to their school are encouraged to continue their action on an individual and collective level (class, school, community) to protect the coast. As a school, they adopt the specific coast and work to inform the public (peers, parents, relatives and stakeholders) on the need for coast protection. Additionally, they organise campaigns in the community to educate on actions that should be followed when visiting the coastal ecosystems, e.g. avoid trampling and vehicle driving on sand dunes, collect garbage, and avoid distracting the living organisms of the coast.

The several one-day experience programmes offered by CYCERE are used as a springboard to transfer the environmental issue back to each student's classroom, home and community. The students' active engagement in the community is an integral part of each programme; it focuses not only on personal environmental behaviour but also on civic participation. These programme characteristics contribute to a broader perspective of EE and expand the followed dimension covering aspects of Education for Environmental Citizenship.

\subsubsection{Youth Clubs as a Youth Engagement Framework: Case Study of Israeli Youth Movements}

The term used for a place where young people can meet and partake in diverse activities is usually one of the following: youth club, centre, group, or movement. Globally, they vary in their activities as well as histories according to cultural, political and social contexts, or voluntary or government support. Youth clubs comprise 
a non-formal learning framework for young people. In many countries these clubs are officially recognised and supported as a framework for youth work that facilitates their capacity building and learning (Goldman et al. 2017; Kiilkowski and Kivijärvi 2015; Forkby and Kiilakowski 2014).

In Israel, youth movements (YMs) are defined as "non-formal organizations of young people active for young people, that have a consolidated vision and membership is voluntary" (Ministry of Education website) and they comprise one of the main agents involved in non-formal education of youth. Principles and requirements common to all formally recognised YMs include:

- education according to universal humanistic values,

- respect for human rights and cultural diversity,

- community and social involvement - contribution to the community and environment,

- cultivating critical thinking, readiness and willingness for change,

- personal and social self-realisation.

Throughout the years, Israeli YMs have contributed to society in general and to youth in particular in a diverse range of areas: promoting social values and human rights, encouraging coexistence, tolerance and social solidarity; reducing social gaps; cultivating leadership, democracy, responsibility and involvement; and reinforcing a sense of attachment to the country (place-attachment).

In view of the environmental-social challenges facing society, Riemer et al. (2014) emphasise the need for effective environmental programmes that engage youth in environmental actions outside the classroom, and are based on a socially transformative approach that promotes, among others, participatory democratic education, real-world contexts, action taking. Consistent with this, Israeli YMs are inherently 'youth engagement programmes' that promote the civic engagement of their members. Thus, they provide a pre-existing youth engagement framework in which the focus of civic engagement can be expanded to address environmental challenges (Goldman et al. 2017). Moreover, Riemer et al. (2014) acknowledge youth as a particularly good target group for civic environmental engagement, in part due to their ability to effectively reach other young people as well as other members of their community. In Israeli YMs, youth educate youth and work within the community; in this aspect they also provide a built-in framework for promoting youth environmental engagement.

Currently, there are 15 officially recognised YMs in which $>250,000$ young people are active (Ministry of Environmental Protection website). Following recommendations deriving from a national survey of environmental education in Israeli YMs (Yavetz et al. 2011; Goldman et al. 2017), various steps have been taken to increase the inclusion of 'environment' within their civic engagement (i.e. strengthen the involvement of YMs in sustainability and contribute to developing young people's Environmental Citizenship). Two noteworthy initiatives with potential for a ripple-effect within the YMs are: 
1. Certifying 'Green' YM branches: Tying this non-formal framework into the national framework of certifying green educational institution ('green schools'). Criteria for certification include: establishing a green-committee (i.e. local 'green' leadership), incorporating means for waste reduction and resource efficiency (i.e. environmental management to reduce the branch's ecological footprint), incorporating environmental values and content into the content of activities, and conducting community projects within the surrounding community that promote active Environmental Citizenship of community members.

2. Providing environmental training to the YM leadership (chief directors of education in each of the YMs, coordinators of the YM branches, and older members who are conducting their year of social-service).

\subsubsection{Learning from Forests: Certification Course Programme for Forest Pedagogy, Austria}

Nearly half of the area of Austria (48\%, 4 million ha.) is covered by forest; it is a country where forest management and the training of forestry staff has long been a tradition. Since the 1990s, Austrian forestry training institutions have offered a certification course called 'Certified Forest Pedagogue' that trains forest educators to make forests, as habitats and economic spaces, more accessible to the public. Forest pedagogy focuses on the dialogue between humans and nature and represents forestry-related environmental education on the diversity and functions of forests. These are current issues, especially as in recent decades conflicts have arisen due to the continuous demand for timber and the growing number of people using forests for recreation purposes.

All aspects relevant to forest pedagogy are discussed during the certification course. The training modules feature a combination of practical strategies (knowledge transfer), a wide range of methods and the development of competence for communication with different target groups depending on their specific needs. Participants' qualifications are developed and tested by the Federal Ministry for Sustainability and Tourism to guarantee a high standard of quality in the transfer of the pertinent knowledge. The validity of the certificate is linked to regular compulsory training events that ensure the specialist's knowledge remains up-to-date. A recertification is required every 5 years.

Up to 80 forest educators are trained in Austria each year, and they provide an important contribution to secondary non-formal education and Environmental Citizenship. In total, more than 1200 certified forest educators are active in Austria and their field of activities is wide. A particular strength of the programme is its interdisciplinary approach, providing both educators and professionals from the forestry sector with the possibility of supporting non-formal environmental education in creative and independent ways after certification. The importance of forest pedagogy is growing, especially with a view to the societal changes accompanying the ongoing trend towards urbanisation. 


\subsubsection{A Museum Lesson on Biodiversity Loss 'Endangered Animals and Plants, Disappearing Ecosystems', The Netherlands}

At the Museon, a science museum in The Hague, The Netherlands, one of the major exhibitions is called 'One Planet'. In this exhibition, visitors learn more about the global societal challenges of our time, such as combatting poverty and hunger and fostering a sustainable world. These challenges are based on the 17 UN Sustainable Development Goals. Education material that accompanies the visit of secondary school students is aimed at teaching them the importance of preserving the earth's biodiversity. They learn how biodiversity originated and how it contributes to food production and health. More specifically, after the visit, students can provide argumentation why biodiversity is important.

One of three perspectives taken in the activities is that of 'politics of nature'. Politics of nature is about a fair distribution of natural resources, understanding what the international political arena looks like and how people deal with the resources. "Key ideas to be included are: sustainable development, north-south relations, respect for pluralism, exploitation, responsibility and democratic decisionmaking" (Van Weelie and Wals 2002, p. 1149).

In the lesson, biodiversity loss is regarded as a complex or 'wicked' problem. Therefore, biodiversity is approached in a systemic way: describing its complexity, as well as its preservation. Moreover, there are multiple ways of studying the impact of biodiversity loss. In one of the games, groups of students pretend they are fishermen, catching fish from a sea in which the number of fish is limited. The person who catches most fish wins. However, when all fish are caught all students have lost (Aartsen, personal communication, 2018).

\subsubsection{The Program for the Recovery and Educational Use of Abandoned Villages. CENEAM. Centro Nacional de Educación Ambiental, Spain}

The Program for the Recovery and Educational Use of Abandoned villages is an educational project complementary to teaching in the classrooms that has been developed in three towns: Umbralejo (Guadalajara), Granadilla (Cáceres) and Búbal (Huesca). The programme is promoted by the Spanish Ministry of Agriculture and Fisheries, Food and Environment, the Ministry of Development, and the Ministry of Education, Culture and Sport.

As most young people live in the urban world, the programme aims to have them reconcile with rural life and have the chance to understand the need for a change of attitudes to ensure the future balance of man with his environment. It includes work in different areas: environmental, health, animation and coexistence, and cultural 
and physical recovery, with a special emphasis on environmental education and the recognition of the important role that the environment plays in the lives of people and the development of society, as well as the need to make decisions and act to avoid deterioration.

The objectives of this programme are, among others, the following:

- Promoting attitudes of respect and tolerance through participation in group activities.

- Helping students appreciate the richness and variety of the natural, social and cultural heritage, respecting their plurality.

- Deepening the knowledge of the human body in order to develop healthy lifestyle habits, both individually and collectively.

- Realising the different possibilities of using free time.

The programme offers four major areas of activities:

- Cultural recovery and maintenance of the towns.

- Environmental education for sustainable development.

- Health.

- Enjoyment and coexistence.

Different workshops on environmental education, animation, anthropology, carpentry, ceramics, corporal expression, dances, health, recycling, video, and photography all help in fostering the development of the mentioned areas. In addition, the towns in general have the following spaces: houses for students and teachers, a dining room and screening room, museums, a library, an outdoor auditorium, a greenhouse, etc.

Within the framework of the development of this programme, each participating institution has a period of between 7 and $10 \mathrm{~h}$ a week to put into practice its participation project, which should also reflect the previous activities that the teaching staff will carry out with the group.

\subsubsection{Environmental Citizenship through Applied Community Service Learning, Afghanistan, Asia}

Environmental citizenship through applied community service learning is a project developed in Afghanistan and seeks to incorporate environmental citizenship and community service learning into curriculum models in formal education or as extracurricular activities in non-formal settings. This project seeks to advance innovation in teaching, learning, and action within school systems- based on local contexts and cultures - for students and communities to create and maintain a more sustainable and peaceful environment. The project's mission is to empower youth and university students to design their own environmental service project in their local com- 
munity and develop exceptional leadership, citizenship, and post-graduate employment skills.

Community service learning pedagogy has strong connections with citizenship education and place-based education and has been adopted in many higher education curriculums worldwide. A wide range of disciplines such as business, engineering, sociology, tourism, environmental studies, have integrated Citizenship Education which can contribute towards the "development of student, faculty, university, and community interactions and capacity in a progressive and transformative manner" (Franklin and Mosavi 2017).

\subsubsection{The Africa Environmental Education and Training Action Plan (AEETAP) 2015-2024}

To address the challenge of environmental degradation within the African continent, UN Environment, in collaboration with other stakeholders, is promoting capacity development for future professionals through environmental education. The Africa Environmental Education and Training Action Plan (AEETAP) 2015-2024, is one of UN Environment's modes of facilitating and promoting environmental awareness, education and training in both formal education and non-formal settings. The Action Plan seeks to promote environmental citizenship through Community/citizenship education programs. Innovative and exciting youth community citizenship programs started to be developed to enthuse youth and their communities to participate in sustainable development actions. These programs are most often provided by NGOs and other community based organizations. These programs seek to empower for out of school youth to become actively engaged in environmental and sustainability related citizen and green economy activities.

The Action Plan advocates for ecosystem resource management; communication and dissemination of environmental material in all forms of education; spatial planning and urban design through green campus designs; sustainable tourism and efficient transport; and water and sanitation, among other green practices (Lotz-Sisitka et al. 2017).

\subsection{Challenges Regarding the Secondary Age Level and the Non-formal Focus and Suggestions for Overcoming Them}

Some challenges arise due especially to the novelty of the concept of Education for Environmental Citizenship. However, some challenges are not exclusive to Education for Environmental Citizenship, but are encountered with regard to EE and EfS. However, since Education for Environmental Citizenship is a contempo- 
rary development of these educational philosophies, the challenges they encounter extend also to Education for Environmental Citizenship.

\section{Challenge 1: Reconnection with Nature}

Reconnecting people with nature can function as a treatment for the global environmental crisis (Ives et al. 2018). Studies have shown that the number of citizens who are unable to link simple ecological and environmental measures to human needs or resources is increasing. A great challenge is to connect our young people to their society and their environment (to take them from the realm of their comfort to the unknown outside). For younger generations, nature is more a abstraction than a reality (Louv 2008). At a time when young people are less connected with their own neighborhood than with peers in other countries (via social networks), we need to encourage youths to leave their homes and experience their neighbourhood reality. Non-formal education programmes need to improve reconnection to nature from the following aspects: (1) material, (2) experiential, (3) cognitive, (4) emotional, and (5) philosophical (Ives et al. 2017). Visiting local natural areas needs to be exploited. Nature promotes youth creativity, stimulating all senses. Youth need to reconnect with the local habitat to feel it as part of their environment; it does not matter if this is a pond, a grassland, or a forest.

\section{Challenge 2: Society's Rules and Youth Formal Participation}

Adult society's rules often institutionalise young people's discrimination as they have not yet the legal adulthood to act as citizens. One Education for Environmental Citizenship goal is to teach young people how to use democratic tools to assert their rights. However, in practice, they are generally unable to do so without an adult, leading to a sense of helplessness. It is interesting to see how desperate a teenager is when he or she discovers that they cannot do something because of 'adults' rules'. In theory, all citizens are equal, but youth citizens are clearly not equal in democracies in terms of formal participation, at least until they reach the legal age (Manning and Ryan 2004). In order to reduce this feeling, it is also important to give them tools to overcome barriers. Mentoring programmes with university students could be part of the solution and create a connection with the following educational level. Moreover, connecting with elderly programmes and society can promote the intergenerational collaboration for EE. Alternatively, it is important to expose young people, via the non-formal educational platform, to those areas of civic participation in which they can contribute to promoting social change.

\section{Challenge 3: Developing a Pedagogical Framework for Non-formal Education for Environmental Citizenship}

A pedagogical framework promoting Education for Environmental Citizenship in non-formal settings should be developed and evaluated. The EEC pedagogical framework should contribute to the development of youths' knowledge, skills, and competencies needed to become ecologically and socially responsible environmental citizens. Best practices based on the Education for Environmental Citizenship pedagogical framework can be developed by expert educators in Education for Environmental Citizenship providing non-formal settings and institutions learning 
experiences and pedagogies that might build students' competencies for deep civic participation, contributing to environmental and social change.

\section{Challenge 4: Educators' Motivation and Professional Development on concerning Education for Environmental Citizenship}

Teachers play a key role in the impact of students' knowledge, values, attitudes, actions and their citizenry towards the environment, thus influencing the outcome of the observed environmental challenges (e.g.: Hungerford 2010; NAAEE 2010; Yavetz et al. 2009; Desjean-Perrotta et al. 2008). Pre-service and in-service training is therefore of particular importance to empower educators to act as formative agents of Environmental Citizenship. This raises questions that need to be answered in order to facilitate educators' engagement in the new initiative of Education for Environmental Citizenship: What competences should educators have in order to be able to engage in Education for Environmental Citizenship? Which Teacher Professional Development models or educational strategies are the most appropriate to train educators for Educating for Environmental Citizenship?

\section{Challenge 5: Time Availability}

Getting youths to participate in non-formal Education for Environmental Citizenship is limited by time availability. Non-formal Education for Environmental Citizenship needs to fit into the tight schedule of today's youth, which differs from that of previous generations (Kleiber and Powell 2005). The time required for non-formal Education for Environmental Citizenship needs and the free time that young people have will impact and shape the structure and communication of any non-formal programme. In order to solve this drawback, the use of weekends could be an alternative, leading to the importance of family involvement.

\section{Challenge 6: Networking}

Within Education for Environmental Citizenship, networking is as a crucial component for achieving environmental change due to its characteristics. For example, networks promote a multidirectional and more symmetrical form of communication. Moreover, networkers want to evolve together with their network partners (at the same time) which encourages them to progress. This is a positive metaphor for the reciprocal relationship between the individual and society and can thus enhance the social responsibility required of environmentally responsible citizens (Goldman et al. 2017).

Acknowledgments This chapter is based on work from Cost Action ENEC - European Network for Environmental Citizenship (CA16229) supported by COST (European Cooperation in Science and Technology). 


\section{References}

Almers, E. (2013). Pathways to action competence for sustainability - Six themes. The Journal of Environmental Education, 44, 116-127.

Amos, R., Knippels, M. C., \& Levinson, R. (in press). Socio-scientific inquiry-based learning: possibilities and challenges for teacher education. In: J. Dillon, M. Evagorou, \& J.A. Nielsen (Eds.), Science Teacher education for responsible citizenship: Towards a pedagogy for relevance through socio-scientific issues. Springer.

Arnold, H., Cohen, F., \& Warner, A. (2009). Youth and environmental action: Perspectives of young environmental leaders on their formative influences. The Journal of Environmental Education, 40, 27-36.

Ballantyne, R., \& Packer, J. (2005). Promoting environmentally sustainable attitudes and behaviors through free-choice learning experiences: What is the state of the game? Environmental Education Research, 11(3), 281-295.

Bell, P., Lewenstein, B., Shouse, A. W., \& Feder, M. A. (Eds.). (2009). Learning science in informal environments: People, places, and pursuits. National Research Council. Committee on learning science in informal environments. Washington, DC: The National Academies Press.

Berkowitz, A. R., Ford, M. E., \& Brewer, C. A. (2005). A framework for integrating ecological literacy, civics literacy, and environmental citizenship in environmental education. In E. A. Johnson \& M. J. Mappin (Eds.), Environmental education and advocacy: Changing perspectives of ecology and education (pp. 227-266). Cambridge: Cambridge University Press.

Bevan, B. (2016). STEM learning ecologies relevant, responsive, and connected. Connected Science Learning, 01-03-2016. Accessed December 2018, from http://csl.nsta.org/2016/03/ stem-learning-ecologies.

Bowers, C. (2002). Toward an eco-justice pedagogy. Environmental Education Research, 8, 21-34.

Capra, F. (1996). The web of life - A new scientific understanding of living systems. New York: Anchor Books.

Cole, A. G. (2007). Expanding the field: Revisiting environmental education principles through multidisciplinary frameworks. The Journal of Environmental Education, 38(2), 35-45.

Dagger, R. (2003). Stopping sprawl for the good of all: The case for civic environmentalism. Journal of Social Philosophy, 34(1), 28-43.

De Carvalho, L. M., \& Lemos de Souza, H. A. (2018). Environmental education research and the political dimension of education for citizenship: The Brazilian context. In G. Reis \& J. Scott (Eds.), International perspectives on the theory and practice of environmental education: A reader (Environmental Discourses in Science Education 3). Cham: Springer.

Desjean-Perrotta, B., Moseley, C., \& Cantu, L. E. (2008). Preservice teachers' perceptions of the environment: Does ethnicity or dominant residential experience matter? The Journal of Environmental Education, 39, 21-32.

Eshach, H. (2007). Bringing in-school and out-of-school learning: Formal, non-formal, and informal education. Journal of Science Education and Technology, 16(2), 171-190.

European Network for Environmental Citizenship - ENEC. (2018). Defining "Education for Environmental Citizenship". Retrieved from http://enec-cost.eu/our-approach/education-forenvironmental-citizenship/, 10 Jan. 2019.

Falk, J. H. (2006). Free-choice environmental learning: Framing the discussion. Environmental Education Research, 11(3), 265-280.

Forkby, T., \& Kiilikoski, T. (2014). Building capacity in youth work: Perspectives and practice in youth clubs in Finland and Sweden. Youth and Policy, 112, 1-17.

Franklin, K., \& Mosavi, S. J. (2017). Environmental citizenship through applied community service learning. Kabul: United Nations Environment.

Goldman, D., Pe'er, S., \& Yavetz, B. (2017). Environmental literacy of youth movement members - Is environmentalism a component of their social activism? Environmental Education Research, 23(4), 486-514. 
Gough, S., \& Scott, W. (2007). Higher education and sustainable development: Paradox and possibility. London: Routledge.

Gruenewald, D. (2003). The best of both worlds: A critical pedagogy of place. Educational Researcher, 32(4), 3-12.

Hadjichambis, A. C., Georgiou, Y., Paraskeva-Hadjichambi, D. P., Ioannou, H., \& Manoli, C. C. (2015). Integrating sustainable consumption into environmental education: A case study on environmental representations, decision making and intention to act. International Journal of Environmental and Science Education, 10(1), 67-86.

Hollweg, K.S., Taylor, J.R., Bybee, R.W., Marcinkowski, T.J., Mcbeth, W.C., \& Ziodo, P. (2011). Developing a framework for assessing environmental literacy. Washington, DC: North American Association for Environmental Education. Available at: https://www.naaee.net.

Hungerford, H. (2010). Environmental education (EE) for the 21st century: Where have we been? Where are we now? Where are we headed? The Journal of Environmental Education, 41, 1-6.

Ives, C. D., Giusti, M., Fischer, J., Abson, D. J., Klaniecki, K., Dorninger, C., Laudan, J., Barthel, S., Abernethy, P., Martín-López, B., Raymond, C. M., Kendal, D., \& Wehrden, H. (2017). Human-nature connection: A multidisciplinary review. Current Opinion in Environmental Sustainability, 26, 106-113.

Ives, C. D., Abson, D. J., von Wehrden, H., Dorninger, C., Klaniecki, K., \& Fischer, J. (2018). Reconnecting with nature for sustainability. Sustainable Science, 13, 1-9.

Jensen, B. B., \& Schnack, K. (1997). The action competence approach in environmental education. Environmental Education Research, 3(2), 163-178.

Kiilakoski, T., \& Kivijärvi, A. (2015). Youth clubs as spaces of non-formal learning: Professional idealism meets the spatiality experienced by young people in Finland. Studies in Continuing Education, 37(1), 47-61.

Kleiber, D. A., \& Powell, G. M. (2005). Historical change in leisure activities during after-school hours. In J. L. Mahoney, R. W. Larson, \& J. S. Eccles (Eds.), Organized activities as contexts of development: Extracurricular activities, after-school and community programs (pp. 23-44). Mahwah: Lawrence Erlbaum Associates.

Knippels, M. C. P. J., \& van Harskamp, M. (2018). An educational sequence for implementing socio-scientific inquiry-based learning. School Science Review, 100(371), 46-52.

Kool, R. (2012). What do we talk about when we talk about 'change' in environmental education? Paper presented at EECOM conference, University of Waterloo.

Kudryavtsev, A., Stedman, R. C., \& Krasny, M. E. (2012). Sense of place in environmental education. Environmental Education Research, 18(2), 229-250.

Levinson, R. (2018). Introducing socio-scientific inquiry-based learning (SSIBL). School Science Review, 100(371), 31-35.

Levinson, R., Knippels, M.C., van Dam, F., Kyza, E. et al. (2017). Science and society in education. Socio-Scientific Inquiry-Based Learning: connecting formal and informal science education with society. https://www.parrise.eu/wp-content/uploads/2018/03/parrise-en-rgb.pdf.

Light, A. (2002). Restoring ecological citizenship. In B. Minteer \& B. P. Taylor (Eds.), Democracy and the claims of nature (pp. 153-172). Lanham: Rowman \& Littlefield.

Light, A. (2003). Urban ecological citizenship. Journal of Social Philosophy, 34(1), 44-63.

Lotz-Sisitka, H., Belliethathan, S., Pradhan, M., Odeke G., and Olewe, B.W., (2017). Africa Environmental Education and Training Action Plan 2015-2024: Strengthening Sustainable Development in Africa, United Nations Environment Programme.

Louv, R. (2008). Last child in the woods: Saving our children from nature-deficit disorder. Chapel Hill: Algonquin Books.

Maniates, M. (2001). Individualization: Plant a tree, buy a bike, save the world. Global Environmental Politics, 1, 31-52.

Manning, B., \& Ryan, R. (2004). Youth and citizenship. Australian Government Department of Family and Community Services. National Youth Affairs Research Scheme. isbn:0 9752498 27. 
Marcinkowski, T. (2010). Contemporary challenges and opportunities in environmental education: Where are we headed and what deserves our attention? Journal of Environmental Education, $41,34-54$.

McKenzie, M. (2008). The places of pedagogy: Or, what we can do with culture through intersubjective experiences. Environmental Education Research, 14, 361-373.

North American Association for Environmental Education. (2009). Guidelines for Excellence Nonformal EE Programs. Mohler, R. A. (2005). Nature-deficit disorder-have children forgotten how to play outdoors? Available at: https://cdn.naaee.org/sites/default/files/gl_nonformal_complete.pdf. Accessed 15 Jan 2019.

North American Association for Environmental Education (NAAEE). (2010). Guidelines for the initial preparation and professional development of environmental educators. Washington, DC: NAAEE. Accessed at: http://resources.spaces3.com/e42d12db-f327-46ca-94c2647060d23e74.pdf.

Orr, D. W. (1992). Ecological literacy - Education and transition to a postmodern world. Albany: State University of New York Press.

Orr, D. W. (2004). Foreword. In S. Sterling (Ed.), Sustainable education: Revisioning learning and change. Schumacher Briefings no. 6 (pp. 7-9). Devon: Green Books Ltd.

Paraskeva-Hadjichambi, D., Korfiatis, K., Hadjichambis, A., \& Arianoutsou, M. (2012). Conservation reasoning and proposed actions for the protection of threatened plant species: Insights from a sample of rural and urban children of Cyprus. Society \& Natural Resources: An International Journal, 25(9), 868-882.

Paraskeva-Hadjichambi, D., Hadjichambis, A. C., \& Korfiatis, K. (2015). How students' values are intertwined with decisions in a socio-scientific issue. International Journal of Environmental \& Science Education, 10(3), 493-513.

Riemer, M., Lynes, J., \& Hickman, G. (2014). A model for developing and assessing youth-based environmental engagement programs. Environmental Education Research, 20(4), 552-574.

Scannell, L., \& Gifford, R. (2010). The relations between natural and civic place attachment and pro-environmental behavior. Journal of Environmental Psychology, 30(3), 289-297.

Schusler, T., \& Krasny, M. (2010). Environmental action as context for youth development. The Journal of Environmental Education, 41(4), 208-223.

Semken, S., \& Freeman, C. B. (2008). Sense of place in the practice and assessment of place-based science teaching. Science Education, 92(6), 1042-1057.

Senge, P. M. (2012). Creating schools for the future, not the past for All students. Leader to Leader, $3(3), 115-118$.

Shutkin, W. A. (2001). The land that could be: Environmentalism and democracy in the twentyfirst century. Cambridge, MA: MIT Press.

Silberman-Keller, D. (2003, April 21-25). Toward the characterization of non-formal pedagogy. Paper presented at the Annual Meeting of the American Educational Research Association. Chicago, IL. Accessed August 8, 2014. http://eric.ed.gov/?id=ED477508

Sirianni, C., \& Friedland, L. A. (2001). Civic innovation in America: Community empowerment, public policy, and the movement for civic renewal. Berkeley, CA: University of California Press.

Smith, G. A. (2007). Place-based education: Breaking through the constraining regularities of public school. Environmental Education Research, 13(2), 189-207.

Stedman, R. C. (2002). Toward a social psychology of place predicting behavior from place-based cognitions, attitude, and identity. Environment and Behavior, 34(5), 561-581.

Tidball, K. G., \& Krasny, M. E. (2010). Urban environmental education from a social-ecological perspective: Conceptual framework for civic ecology education. Cities and the Environment, $3(1)$.

Tuck, E., McKenzie, M., \& McCoy, K. (2014). Land education: Indigenous, post-colonial, and decolonizing perspectives on place and environmental education research. Environmental Education Research, 20(1), 1-23. 
UNESCO. (1978). Final Report - Intergovernmental Conference on Environmental Education. Organized by UNESCO in cooperation with UNEP, Tbilisi, USSR, October 14-26, 1977. Paris: UNESCO ED/MD/49.

Van Weelie, D., \& Wals, A. E. J. (2002). Making biodiversity meaningful through environmental education. International Journal of Science Education, 24(11), 1143-1156. https://doi. org/10.1080/09500690210134839.

Vaske, J. J., \& Kobrin, K. C. (2001). Place attachment and environmentally responsible behavior. The Journal of Environmental Education, 32(4), 16-21.

Vorkinn, M., \& Riese, H. (2001). Environmental concern in a local context: The significance of place attachment. Environment and Behavior, 33(2), 249-263.

Wals, A., \& Jickling, B. (2009). A framework for young people's participation in sustainability. In P. B. Corcoran \& P. Osano (Eds.), Young people, education, and sustainable development: Exploring principles, perspectives, and praxis. Wageningen: Wageningen Academic Publishing.

Yavetz, B., Goldman, D., \& Pe'er, S. (2009). Environmental literacy of pre-service teachers in Israel: A comparison between students at the onset and end of their studies. Environmental Education Research, 15(4), 393-415.

Yavetz, B., Goldman, D., \& Pe'er S. (2011). Environmental education in youth movements: A survey of environmental awareness and motivation towards environmental behavior and recommendations for enhancing environmental activity within these organizations. Research Report no. 8-202, Jerusalem: The Ministry of Environmental Protection [in Hebrew].

Open Access This chapter is licensed under the terms of the Creative Commons Attribution 4.0 International License (http://creativecommons.org/licenses/by/4.0/), which permits use, sharing, adaptation, distribution and reproduction in any medium or format, as long as you give appropriate credit to the original author(s) and the source, provide a link to the Creative Commons license and indicate if changes were made.

The images or other third party material in this chapter are included in the chapter's Creative Commons license, unless indicated otherwise in a credit line to the material. If material is not included in the chapter's Creative Commons license and your intended use is not permitted by statutory regulation or exceeds the permitted use, you will need to obtain permission directly from the copyright holder.

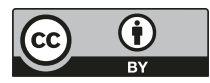

